PERSONALISED LEARNING

FOR THE LEARNING

PERSON 
This page intentionally left blank 


\title{
PERSONALISED LEARNING \\ FOR THE LEARNING PERSON
}

\author{
RUPERT WARD \\ University of Huddersfield, UK
}

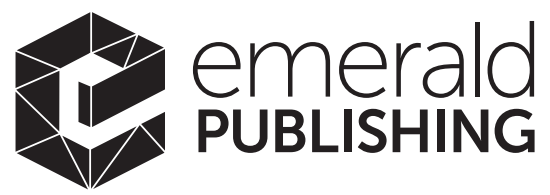

United Kingdom - North America - Japan - India Malaysia - China 
Emerald Publishing Limited

Howard House, Wagon Lane, Bingley BD16 1WA, UK

First edition 2020

(C) 2020 Rupert Ward

Published under exclusive licence by Emerald Publishing Limited.

\section{Reprints and permissions service}

Contact: permissions@emeraldinsight.com

No part of this book may be reproduced, stored in a retrieval system, transmitted in any form or by any means electronic, mechanical, photocopying, recording or otherwise without either the prior written permission of the publisher or a licence permitting restricted copying issued in the UK by The Copyright Licensing Agency and in the USA by The Copyright Clearance Center. Any opinions expressed in the chapters are those of the authors. Whilst Emerald makes every effort to ensure the quality and accuracy of its content, Emerald makes no representation implied or otherwise, as to the chapters' suitability and application and disclaims any warranties, express or implied, to their use.

British Library Cataloguing in Publication Data

A catalogue record for this book is available from the British Library

ISBN: 978-1-78973-150-7 (Print)

ISBN: 978-1-78973-147-7 (Online)

ISBN: 978-1-78973-149-1 (Epub)

ISOQAR certified

Management System,

awarded to Emerald

for adherence to

Environmental

standard

ISOQAR

ISO 14001:2004.

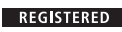

Certificate Number 1985

ISO 14001

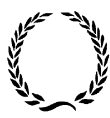

INVESTOR IN PEOPLE 
In loving memory of Liz Lynch, the most wonderful person I ever met.

I hope this book inspires others in the way she inspired me. Dedicated to all those whose capabilities are yet to be fully nurtured, recognised or realised;

and to all those who believe, like Liz, in the goodness and wonder within us all. 
This page intentionally left blank 


\section{CONTENTS}

List of Figures ix

List of Tables $\quad$ xi

Biography xiii

Foreword $\quad x V$

Acknowledgements $\quad x \times i$

Introduction 1

1. Personalised Learning 3

2. Functional Learning 19

3. Learning Information 41

4. Learning Intelligence 59

5. Learning Sensitivity 77

6. Learning Fitness 97

7. Learning Expertise 115

8. Learning Choice 131

9. Learning ldea 151

10. Personalised Learning for the Learning Person 177

References 199

Index 255 
This page intentionally left blank 


\section{LIST OF FIGURES}

Figure 1. The Metalearning Model.

16

Figure 2. Functional Learning within the

Metalearning Model.

20

Figure 3. Kolb's (1984) Experiential Learning Cycle.

Figure 4. Learning Information within the Metalearning Model.

Figure 5. Learning Memory Model. 45

Figure 6. Learning Decision-making. 48

Figure 7. Learning Intelligence within the Metalearning Model.

Figure 8. Tripartite Learning Model. 65

Figure 9. Integrated Learning Behaviour. 75

Figure 10. Learning Sensitivity within the Metalearning Model. $\quad 78$

Figure 11. Environmental Review. 80

Figure 12. Educational Fluency as Part of University Student Retention. 
Figure 13. Learning Fitness within the Metalearning Model.

Figure 14. Performance Appraisal.

102

Figure 15. Performance Attribution.

107

Figure 16. Learning Expertise within the Metalearning Model.

Figure 17. Expert and Novice Designers.

Figure 18. Self-Regulated learning.

Figure 19. Learning Choice within the Metalearning Model.

Figure 20. Self-Determined Motivation.

Figure 21. Self-Regulated Learning.

Figure 22. iDEA Badge Categories.

Figure 23. Badge Storyboarding.

Figure 24. Badge Example 1.

Figure 25. Badge Example 2.

Figure 26. Badge Example 3.

Figure 27. Badge Example 4.

Figure 28. Badge Example 5.

Figure 29. Badge Example 6.

Figure 30. Badge Example 7.

Figure 31 . Badge Example 8.

Figure 32. Badge Progression Example.

Figure 33. The Metalearning Model. 


\section{LIST OF TABLES}

Table 1. Perception-Performance Choices.

134

Table 2. Badge Checklist.

161

Table 3. Personalised Learning Criteria from

Schooling for Tomorrow (2006) and OECD (2018). 
This page intentionally left blank 


\section{BIOGRAPHY}

Rupert Ward is a former Special Adviser to the Royal Household and Project Lead for the Inspiring Digital Enterprise Award (iDEA), one of the world's most successful free educational technologies. He is also a UK National Teaching Fellow and Principal Fellow of the Higher Education Academy. He co-authored the University of Huddersfield's highly successful assessment and feedback strategy, and has been part of teams recognised nationally seven times in seven years in areas including enterprise, customer service excellence, student experience (National Acquisitions Group Award for Excellence and Guardian Award for Student Experience) and assessment and feedback (Highly Commended, ICT Innovation of the Year, THE Leadership \& Management Awards). An avid learner, he is currently completing his eighth postgraduate qualification across a range of disciplines. Rupert is Professor of Learning Innovation and Associate Dean (International) within the School of Computing and Engineering at the University of Huddersfield. He is a member of the British Computer Society Accreditation Committee, a former elected board member of the UK Council for Professors and Heads of Computing, a Fellow of the British Computer Society, a Chartered Engineer, a Chartered Manager and a Chartered IT Professional. 
This page intentionally left blank 


\section{FOREWORD}

We live in a world where the kind of things that are easy to teach and test have also become easy to digitise and automate. The industrial age taught us how to educate second-class robots, people who learn in standardised settings and become good at repeating what we tell them. In this age of accelerations, we need to think harder about what makes us first-class humans, how we complement, not substitute, the artificial intelligence we have created in our computers and how we build a culture that facilitates learning, unlearning and re-learning throughout life. This implies making learning systems less like industrial farms and more like a zoo, bringing out the features that make each person special rather than developing standardised ways of thinking that technology will make redundant. It is about getting from numbers, to names to needs, and becoming better at respecting the identity, context and culture of every learner. That is what this book on personalised learning is about.

And it conveys an important imperative. These days, algorithms behind social media are sorting us into groups of like-minded individuals. They create virtual bubbles that amplify our views and leave us insulated from divergent perspectives; they homogenise opinions and polarise our societies. Tomorrow's learning systems will need to help learners to think for themselves and join others, with empathy, in work 
and citizenship. They need to help learners develop a strong sense of right and wrong, a sensitivity to the claims that others make on us, and a grasp of the limits on individual and collective action. At work, at home and in the community, people will need a deep understanding of how others live, in different cultures and traditions, and how others think, whether as scientists or artists. And whatever tasks machines may be taking over from humans at work, the demands on our knowledge and skills to contribute meaningfully to social and civic life will keep rising.

The growing complexity of modern living for individuals, communities and societies, suggests that the solutions to our problems will also be complex: in a structurally imbalanced world, the imperative of reconciling diverse perspectives and interests, in local settings with often global implications, will require people to become adept in handling tensions, dilemmas and trade-offs. Striking a balance between competing demands - equity and freedom, autonomy and community, innovation and continuity, efficiency and democratic process - will rarely lead to an either/or choice or even a single solution. Individuals will need to think in a more integrated way that recognises interconnections. Empathy, adaptability and trust are underpinning this.

Creativity in problem-solving requires the capacity to consider the future consequences of one's actions, evaluate risk and reward, and assume accountability for the products of one's work. This suggests a sense of responsibility, and of moral and intellectual maturity, with which we can reflect upon and evaluate our actions in the light of experiences and personal and societal goals.

The conventional approach in education is often to break problems down into manageable bits and pieces and then to teach learners how to solve these bits and pieces. But modern societies create value by synthesising different fields of 
knowledge, making connections between ideas that previously seemed unrelated. That requires being familiar with and receptive to knowledge in other fields.

In today's education systems, students typically learn individually and at the end of the school year, we certify their individual achievements. But the more interdependent the world becomes, the more we need great collaborators and orchestrators. Innovation is now rarely the product of individuals working in isolation, but rather an outcome of how we mobilise, share and integrate knowledge. The well-being of societies depends increasingly on people's capacity to take collective action. Learning systems therefore need to become better at helping students learn to develop an awareness of the pluralism of modern life. That means teaching and rewarding collaboration as well as individual academic achievement, enabling students both to think for themselves, and to act for and with others. Personalised learning and collaborative learning are two sides of the same coin.

The challenge is that developing these cognitive, social and emotional capabilities requires a very different approach to learning and teaching and a different calibre of teachers. Where teaching is about imparting prefabricated knowledge, education systems can afford low teacher quality. And when teacher quality is low, governments tend to tell their teachers exactly what to do and exactly how they want it done, using an industrial organisation of work to get the results they want. The challenge is to make teaching a profession of advanced knowledge workers who work with a high level of professional autonomy and within a collaborative culture.

But such people will not work as exchangeable widgets in education systems organised as Taylorist workplaces that rely mainly on administrative forms of accountability, and bureaucratic command-and-control systems to direct their work. To attract the people they need, modern learning 
systems need to transform the type of work organisation to one in which professional norms of control replace bureaucratic and administrative forms of control. The past was about received wisdom; the future is about user-generated wisdom.

Instruction in the past was subject-based; instruction in the future needs to be more project-based, building experiences that help students think across the boundaries of subject matter disciplines. The past was hierarchical; the future is collaborative, recognising both teachers and students as resources and co-creators.

In the past, different students were taught in similar ways. Now learning systems need to embrace diversity with differentiated approaches to learning. The goals of the past were standardisation and compliance, with students educated in age cohorts, following the same standard curriculum, all assessed at the same time. The future is about building instruction from students' passions and capacities, helping students personalise their learning and assessments in ways that foster engagement and talent. It's about encouraging students to be ingenious.

Learning systems need to better recognise that individuals learn differently, and in different ways at different stages of their lives. They need to create new ways of providing education that take learning to the learner and that are most conducive to students' progress. Learning is not a place, but an activity.

In the past, schools were technological islands, with technology often limited to supporting existing practices, and students outpacing schools in their adoption and consumption of technology. Future learning systems need to use the potential of technologies to liberate learning from past conventions and connect learners in new and powerful ways, with sources of knowledge, with innovative applications and with one another. 
The past was also divided - with teachers and content divided by subjects and students separated by expectations of their future career prospects; with schools designed to keep students inside, and the rest of the world outside; with a lack of engagement with families and a reluctance to partner with other schools. The future needs to be integrated - with an emphasis on the inter-relation of subjects and the integration of students. It also needs to be connected, so that learning is closely related to real-world contexts and contemporary issues, and open to the rich resources in the community. Effective learning environments are constantly creating synergies and finding new ways to enhance professional, social and cultural capital with others. They do that with families and communities, with higher education, with businesses and especially with other learning environments.

None of this is easy, and none of this can be done overnight. But it must be done and the task is not about making the impossible possible, but about making the possible attainable.

Andreas Schleicher

Director for Education and Skills, and Special Advisor on Education Policy to the Secretary-General at the Organisation for Economic Co-operation and Development (OECD), Paris. 
This page intentionally left blank 


\section{ACKNOWLEDGEMENTS}

Thank you first and foremost to Janet and Robin for being such fantastic parents. I have learnt so much as a person from you both over the years. Thank you also to my close friends and family, including Nick, Andy, Hannah, Deni, Dave and Rachel. Thank you also to those who provided feedback on my various drafts, including Ian, Mel and Ste.

Professionally I would like to thank all those who made iDEA what it is today and who gave me the opportunity and freedom to work on something so meaningful. In particular, I would like to thank His Royal Highness and Amanda for their support throughout my time at Buckingham Palace, and Kerensa both for driving iDEA to the success it has become. Thank you also to Bob for being such a great leader, guide and mentor for myself and many others.

The iDEA community is vast, and so apologies if I miss anyone out from the following list. I'd like to thank Leila Khouja Walker and the Nominet team for developing the first iDEA initiative. Graeme Lawrie for co-creating the new version of iDEA and developing the curriculum mapping as we went through a steep early learning curve. The students and staff from the University of Huddersfield who supported the initial prototype website where so much of iDEA's structures and processes were understood and developed. These included Alex Beech, Aneeque Hamid, Callum Eddisford, 
Daniel Park, Dom Hanson, Eva Glover, Heidi Garthwaite, Jess Allen, Joshua Michael, Liam Turner, Libby Teagle, Luke Hall, Nathan Kettle, Paul Marshall, Sarah Miller, Umair Ali, Wael Aziz, Xiaozhou Song, Dave Wilson, Duke Gledhill, Matthew Mantle, Michael O'Grady, Steve Wade and Wolfgang Faber. Rich Martell and the Floxx team for developing such a great website and supporting so much of the development of iDEA and its underlying technical infrastructure. Robin Worrall and the Seven Hills team for his design and branding work. The many wonderful badge developers, including those whose work is highlighted in Chapter 9, namely Sam Vestby-Clarke and his team at Toasted Digital; Tony Brennand, Jeremy Jones and their team at Digital Marmalade; David Curtis and the team at Wakelet; James Rossell, Chloe Cameron and their team at Wirehive; John Belo, Katie Li and their team at Salesforce, and Alex Enache. The Special Advisers who established and grew the iDEA charitable trust, including Sam Barton and Richard Trueman. The iDEA board for their input and guidance. The core iDEA launch team, Kerensa, Lorenzo Tucker and Pritpal Singh, and, at various times, Fred Parry. Further iDEA team members that have carried the baton since launch, driving its growth and development, including Donovan Hare, David Wright, Katie Rushworth and Polly Morgan. The office team, whose support and feedback were invaluable, including Sharon, Lorna and Danielle, and Pete Frost at the Leander Gym who inspired the Learning Fitness chapter. Andreas, thank you for writing the foreword for this book. Thanks also to the many supporters, guides and champions of iDEA in the United Kingdom and overseas, including Naomi Timperley, Michelle Ovens, Michael Osbaldeston, Clive Gardiner, Mark Yorke, Steve Molyneux, Victoria Tuffill, Ben Towers, Jack Parsons, Alison Edgar, Maggie Philbin, Annika Small, Gi Fernando, Alison McKenzie-Folan, Liz Williams, Jeff McCarthy, Mark 
Hill, Nicola Mounsey, Caroline Keep, Michael Hayman, Charlotte Kirby and Melissa Di Donato. iDEA has been successful because of the richness of input from everyone. It's been a real team effort throughout, a true learning community. Thank you all for your enthusiasm, contributions, passion and support in developing such a wonderful initiative, and bringing joy and opportunity to so many. I hope you all enjoy reading this book. 